\title{
Characterization of Biobased Polyurethane Foams Employing Lignin Fractionated from Microwave Liquefied Switchgrass
}

\author{
Xingyan Huang, ${ }^{1,2}$ Cornelis F. De Hoop, ${ }^{1}$ Jiulong Xie, \\ Chung-Yun Hse, ${ }^{3}$ Jinqiu $\mathrm{Qi}^{2}{ }^{2}$ and Tingxing $\mathrm{Hu}^{2}$ \\ ${ }^{1}$ School of Renewable Natural Resources, Louisiana State University Agricultural Center, Baton Rouge, LA 70803, USA \\ ${ }^{2}$ College of Forestry, Sichuan Agricultural University, Chengdu 611130, China \\ ${ }^{3}$ Southern Research Station, USDA Forest Service, Pineville, LA, 71360, USA \\ Correspondence should be addressed to Jiulong Xie; jxie6@lsu.edu
}

Received 13 June 2017; Accepted 27 July 2017; Published 24 August 2017

Academic Editor: Chaoqun Zhang

Copyright (C) 2017 Xingyan Huang et al. This is an open access article distributed under the Creative Commons Attribution License, which permits unrestricted use, distribution, and reproduction in any medium, provided the original work is properly cited.

\begin{abstract}
Lignin samples fractionated from microwave liquefied switchgrass were applied in the preparation of semirigid polyurethane (PU) foams without purification. The objective of this study was to elucidate the influence of lignin in the PU matrix on the morphological, chemical, mechanical, and thermal properties of the PU foams. The scanning electron microscopy (SEM) images revealed that lignin with 5 and $10 \%$ content in the PU foams did not influence the cell shape and size. The foam cell size became larger by increasing the lignin content to $15 \%$. Fourier transform infrared spectroscopy (FTIR) indicated that chemical interactions occurred between the lignin hydroxyl and isocyanate revealing that lignin was well dispersed in the matrix materials. The apparent density of the foam with $10 \%$ lignin increased by $14.2 \%$ compared to the control, while the foam with $15 \%$ lignin had a decreased apparent density. The effect of lignin content on the mechanical properties was similar to that on apparent density. The lignin containing foams were much more thermally stable than the control foam as evidenced by having higher initial decomposition temperature and maximum decomposition rate temperature from the thermogravimetric analysis (TGA) profiles.
\end{abstract}

\section{Introduction}

As an important engineering material, polyurethane foam (PU foam) has been widely used in automotive industry, insulating panel, construction, and so on [1]. Currently, the research on the alternative of petroleum-based polyol, a main chemical component to manufacture PU foam with eco-friendly biopolyol sources such as biodiesel residues, has attracted an increasing attention [2], due to the rapid depletion of fossil fuels.

Vegetable oil composed of triglycerides of long chain fatty acids has great potential for the synthesis of polyols. In recent years, a series of vegetable oils have been successfully applied in the preparation of biobased PU foams, such as modified oils from soybean and castor oils [3-5]. Meanwhile, chemical platforms derived from nonfood resources were also modified and used as alternative components to achieve highly functional biobased foams. Lignocellulosic biomass composed of cellulose, hemicellulose, and lignin is a valuable and worldwide accessible bioresource which can provide alternative chemicals via proper conversion processes. Recent achievements in biomass thermochemical conversion techniques have stimulated great interests in the integrated utilizations of lignocellulosic biomass for the production of hydroxyl-rich biopolyols. The achieved biopolyols by liquefaction have high hydroxyl functionalities and great promising properties in the production of PU foams [6]. A large variety of lignocellulosic biomass such as bamboo [7], wheat straw [8], and soybean straw [9] has been liquefied into liquid polyols for the preparation of PU foams. Instead of converting lignocellulosic biomass into biopolyols as a core reactant in the synthesis of foams, other researchers directly added bioderived materials such as wood pulp fiber [10] and nanoparticle lignin [11] into matrix materials as reinforcing filler in the biofoams.

Lignin is composed of three different types of phenylpropane units. It is a three-dimensional amorphous phenolic 
polymer which fills the space between cellulose and hemicellulose and cross links with hemicellulosic polysaccharides [12]. Lignin generally features an irregular structure with a highly condensed cross-linked polymer network providing the biomass with mechanical strength as well as rigidity to resist external forces [13]. However, lignin from pulping or biorefinery industries is currently an underutilized waste product. About 225 million tons of lignin generation is expected from the cellulosic alcohol industry in the United States in the near future, and only $2 \%$ is used for valueadded applications [14]. In order to address the resource waste problem and to enhance the commerciality of the bioethanol industry, a number of studies have been conducted to use lignins as raw feedstocks for production of biobased materials. Lignin was added to poly lactic acid (PLA) matrix to fabricate PLA-lignin composites for use as packaging materials [15]. The liquefied lignin was applied for the substitution of petro derived ployol to prepare flexible polyurethane foams [16]. Organosolv and Kraft lignin were used as hydroxyl sources to replace polyols for the production of PU foams [17, 18]. Meanwhile, some chemical strategies such as oxypropylation [19], urethane modification [20], and liquefaction [21] were also used to modify lignin macromolecules, and the modified lignin was incorporated into the polyurethane matrix for production of high biocontent materials. Although recent research work on lignin-based foam has achieved great progress, some of these synthesized foams could not show comparable properties to commercial ones. Thus, intensive work is still needed to find efficient ways to transform lignin into highly functional materials for market applications.

In the past decades, research for alternate fuel resources to meet the ever-increasing energy demand and to avoid dependence on fossil fuel has attracted the attention of researchers worldwide. Switchgrass (Panicum virgatum), which occurs naturally from $55^{\circ} \mathrm{N}$ latitude to central Mexico [22], is considered as a promising crop for a large region of the Unite States. Switchgrass shows promise due to its high productivity, suitability for marginal land quality, low water and nutritional requirements, environmental benefits, and flexibility for multipurpose uses [23]. It has been used over other crops for conversion to bioenergy within the United States and was identified by the US Department of Energy as a model herbaceous energy crop [24]. Nowadays, fast pyrolysis and enzymatic hydrolysis have been used as common strategy for energy conversion employing switchgrass [25, 26]. Recent research on alkaline pretreatment of switchgrass for lignin removal and sugar retentions for economic valuable cellulosic ethanol production was reported by Karp et al. [27]. Meanwhile, liquefaction was also applied in the integrated utilizations of switchgrass for biobased epoxy resins [28]. In our previous study, we optimized a system to selectively liquefy the lignin in lignocellulosic biomass for production of carbohydrate polymers. In order to verify the commercial potential of this novel biomass utilization process, the lignins from the selective liquefaction process were recovered and the physicochemical properties of the lignin samples were examined [15]. Previous results showed that the recovered switchgrass lignin retained its original core structure, high thermal stability, and good solubility in common organic solvents. Thus, in order to verify whether the recovered lignin had potential for PU foam, lignins were introduced into the PU matrix for the preparation of lignin containing semirigid PU foams. The specific objective of this study was to investigate the influence of lignin on the morphological, mechanical, and thermal properties of the synthesized foams. The aim of this research was to provide a new approach for the utilizations of biorefinery industrial lignins.

\section{Experimental}

2.1. Material and Chemicals. Switchgrass (Panicum virgatum) was harvested from agricultural land in central Louisiana, USA. The whole switchgrass straw including leaves was reduced to particles using a Thomas Wiley Laboratory mill. The particles were screened to collect particles that passed through a 20-mesh sieve and then retained on a 40 -mesh sieve and then dried to a constant weight in an oven maintained at $80^{\circ} \mathrm{C}$. The dried particles were stored in polyethylene bags and used without further treatment. All acids, glycerol, and methanol used were of reagent grade and obtained from commercial sources.

2.2. Microwave Liquefaction. Microwave selective liquefaction was carried out in a Milestone MEGA laboratory microwave oven. Mixed glycerol and methanol at a ratio of $2 / 1(w / w)$ was used as the solvent at a solvent to switchgrass ratio of $4 / 1(w / w)$. Sulfuric acid (1.75\% of solvent weight) was used as the catalyst. A typical reaction mixture consisting of $2 \mathrm{~g}$ of switchgrass particles, $8 \mathrm{~g}$ of solvent, and $0.14 \mathrm{~g}$ of sulfuric acid was loaded in Teflon vessels with a magnetic stirring bar. The Teflon vessels were then placed on the rotor tray inside the microwave cavity. The temperature was monitored using an ATC-400FO automatic fiber optic temperature control system. Based on monitored temperature, the output power was autoadjusted during liquefaction. In this study, the temperature was increased from room temperature to $120^{\circ} \mathrm{C}$ and then was kept constant for $4 \mathrm{~min}$. The resulting reaction mixtures were dissolved in methanol and then vacuumfiltered through Whatman number 4 filter paper.

The filtrated liquid was evaporated at $45^{\circ} \mathrm{C}$ under vacuum to remove methanol, and then distilled water $[10 / 1(\mathrm{w} / \mathrm{w})]$ was added to the obtained liquid. The mixture was stirred thoroughly with a glass rod. Afterwards, the mixture was centrifuged at $5000 \mathrm{rpm}$ for $10 \mathrm{~min}$. The precipitates were dried at $30^{\circ} \mathrm{C}$ for $12 \mathrm{~h}$. The samples were kept in ambient conditions for further usage.

2.3. Preparation of PU Foams. The control PU foam was prepared using a one-step method according to a previous used method [29]. A typical mixture of PEG-400/glycerol $(8.0 \mathrm{~g})$, catalyst (dibutyltin dilaurate, $0.16 \mathrm{~g})$, blowing agents (water, $0.54 \mathrm{~g}$ ), and surfactant (Dow corning 193, $0.16 \mathrm{~g}$ ) was premixed thoroughly in a beaker with a mechanical stirrer for $15 \mathrm{~s}$. Afterwards, $12.8 \mathrm{~g}$ of isocyanate ([NCO]/[OH] ratio, 0.6) was added to the premixture and the combination was stirred with a high-speed agitator at a stirring speed of $3600 \mathrm{rpm}$. Immediately afterwards, the resultant mixture was poured 
into an open cylindrical mold and was allowed to freely rise at room conditions. The obtained foams were allowed to cure at room temperature for $1 \mathrm{~h}$. For the preparation of lignin containing foams, desired lignin samples were dissolved in PEG/glycerol blend at the mass rate of 5, 10, and $15 \%$ (based on PEG/glycerol mixture), and then the mixture was compounded with other components following the same procedure for the control foam.

2.4. Characterization. The foam samples were crumbed into powder prior to the chemical structure analysis by using FTIR. The FTIR analysis was performed by a Nicolet Nexus 670 spectrometer equipped with a Thermo Nicolet Golden Gate MKII Single Reflection ATR accessory. Data collection was performed with a $4 \mathrm{~cm}^{-1}$ spectral resolution and 32 scans were taken per sample. The surface morphology of the foam was observed using scanning electron microscopy (SEM, NeoScope JCM-5000, NiKon Instruments Inc.). Test samples were coated with gold using a vacuum sputter coater before being subjected to the SEM analysis. TG/DTG analysis was conducted with a thermal analyzer, TGA (Q50, TA Instruments), to simultaneously obtain thermogravimetric data. About $5 \mathrm{mg}$ of powder sample was loaded on the platinum crucible and analyzed by the thermal analyzer. Pyrolysis was terminated at $800^{\circ} \mathrm{C}$ with a heating rate of $20^{\circ} \mathrm{C} / \mathrm{min}$ under a flow of $60 \mathrm{~mL} / \mathrm{min}$ of nitrogen gas. The apparent density of the PU foam was measured at $23^{\circ} \mathrm{C}$ with $50 \%$ relative humidity according to ASTM D1622-03. The size of the specimen was $30 \mathrm{~mm} \times 30 \mathrm{~mm} \times 30 \mathrm{~mm}$ (length $\times$ width $\times$ thickness). Five specimens were used for per sample and the average value was reported. The mechanical properties were characterized by the compressive strength and compressive modulus. The size of the specimen used for compressive strength was $30 \mathrm{~mm} \times 30 \mathrm{~mm} \times 30 \mathrm{~mm}$ (length $\times$ width $\times$ thickness). The test was performed using an Instron testing machine (Instron 4465), with a load of $2 \mathrm{KN}$ at a crosshead speed of $2.5 \mathrm{~mm} / \mathrm{min}$. Compressive strength at $10 \%$ strain and compressive modulus were performed according to ASTM D 1621-10. For each sample, five specimens were tested, and an average value was taken along with the standard deviation.

\section{Results and Discussion}

3.1. Morphological Structures. The cross-section structure of the PU foam samples was characterized by SEM images. As presented in Figure 1, both the control (Figure 1(a)) and the lignin containing (Figures $1(\mathrm{~b})-1(\mathrm{~d})$ ) PU foams exhibited a honeycomb structure with closed cells. The control PU foams had almost regular cell size and distribution with a negligible quantity of broken cell walls. Despite the broken cell walls, the pure polyol PU foams with a light yellow color had no significant difference in cell structures from the ones with $5 \%$ lignin, indicating that the influence of lignin on the foam structure was insignificant with less than $5 \%$ lignin content in the foam. With the introduction of lignin into the PU matrix, the PU foam color became brown and the cell diameter tended to be larger.

The cell diameter and number of cells by surface area $(n)$ of the PU foams were measured and the values are listed in
Table 1. From Table 1, the polyol PU foams had relatively small cell diameter and high number of cells by surface area $(n)$. The cell diameters of foams with 5, 10, and 15\% lignin were 523.1, 521.3 , and $838.8 \mu \mathrm{m}$, respectively, and the number of cells by surface area $(n)$ was $1.82,1.87$, and $1.02 \mathrm{~N} / \mathrm{mm}^{2}$, respectively. According to the ANOVA analysis, significant differences $(p<0.01)$ in the cell diameter were found between 15\% lignin foam and the others. The result revealed that the addition of $15 \%$ lignin into the PU matrix had a significant effect on the foam cellular structures. The alteration in the cell structure may be due to the fact that high lignin content affected the cell nucleation process in the preparation of PU foams [30]. Similar results were also found by Pan and Saddler [17], who reported that the increase of ethanol organosolv lignin ratio in petroleum-based polyol resulted in particularly large cells (bubbles). However, this finding regarding cell diameter was quite different from Luo et al. [3]. This may be due to the character variations among the polyols and lignins employed in the foam preparation. A combination of PEG/glycerol blends and depolymerized switchgrass lignin were used as hydroxyl sources in this study whereas soy oil/lignin powder was used as the reaction feedstock in Luo et al.'s research [3].

3.2. Chemical Structure. FTIR spectra were used to characterize the chemical structures of polyol, lignin, MDI (Figure 2(a)), and the synthesized PU foams (Figure 2(b)). As shown in Figure 2(b), the polyol was confirmed by the absorption bands at $3330 \mathrm{~cm}^{-1}(\mathrm{OH}$ stretching) and $2870 \mathrm{~cm}^{-1}$ (C-H stretch). Switchgrass lignin was confirmed by the main characteristic bands at $1599 \mathrm{~cm}^{-1}$ (aromatic ring vibration), $1510 \mathrm{~cm}^{-1}$ (aromatic skeletal vibration), $1456 \mathrm{~cm}^{-1}$ (C-H deformation), and $1220 \mathrm{~cm}^{-1}$ (C-O stretching in phenol and ethers) [15]. An intensity band at $2240 \mathrm{~cm}^{-1}$ attributed to the NCO group was found on the spectrum of MDI. The absorption bands of urethane moieties such as $3310 \mathrm{~cm}^{-1}(\mathrm{NH}$ stretching vibration), $1703 \mathrm{~cm}^{-1}(\mathrm{C}=\mathrm{O}), 1599 \mathrm{~cm}^{-1}(\mathrm{CO}-\mathrm{NH}$ variation), $1510 \mathrm{~cm}^{-1}$ (NH bending vibration), and $1220 \mathrm{~cm}^{-1}$ (O-CO stretching vibration) were identified in the spectra of the PU foams. No absorption band was observed at $2240 \mathrm{~cm}^{-1}$ assigned to NCO groups in the spectra of the PU foams, which indicated that the isocyanate group was completely consumed with the production of urethane or urea linkages. Meanwhile, the intensity of both the peaks at 3330 and $2870 \mathrm{~cm}^{-1}$ in the spectrum of the polyols was weakened and became broad. These results indicated the occurrence of the efficient chemical interactions between the polyols and MDI.

Compared to the spectrum of the control foam, no extra band was introduced by the addition of lignin into the PU foam (Figure 2(b)). There was a slight position shift of carbonyl stretching vibration band from 1703 to $1707 \mathrm{~cm}^{-1}$ by increasing the amount of lignin in the PU. This result could allow the chemical interactions that occurred between the hydroxyl bonds from the lignin and the NCO groups [31]. From this result, it can be speculated that lignin was well miscible with the PU foam matrix at a molecular level. Moreover, the bands at 1599 and $1510 \mathrm{~cm}^{-1}$ which also corresponds to the aromatic structure of lignin presented 


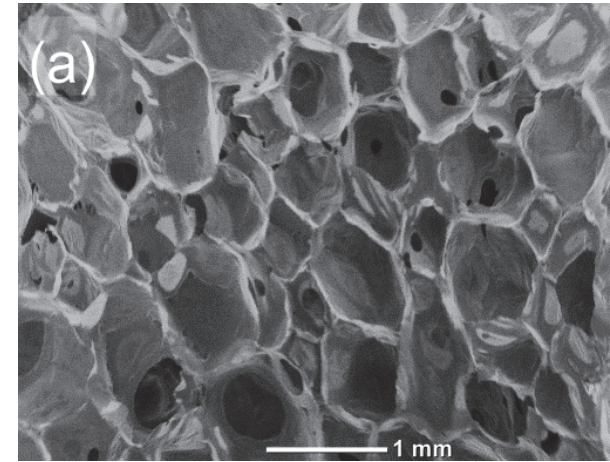

(a)

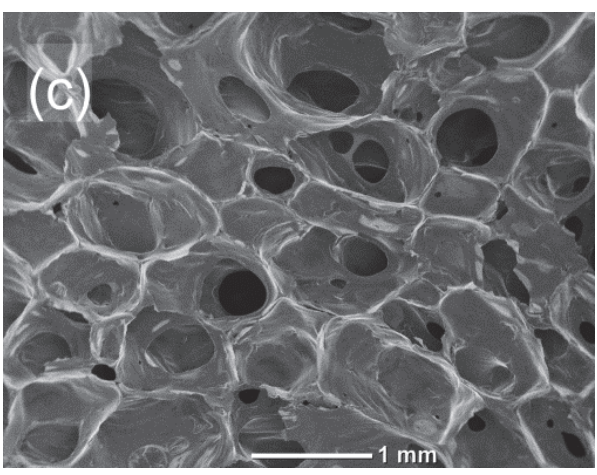

(c)

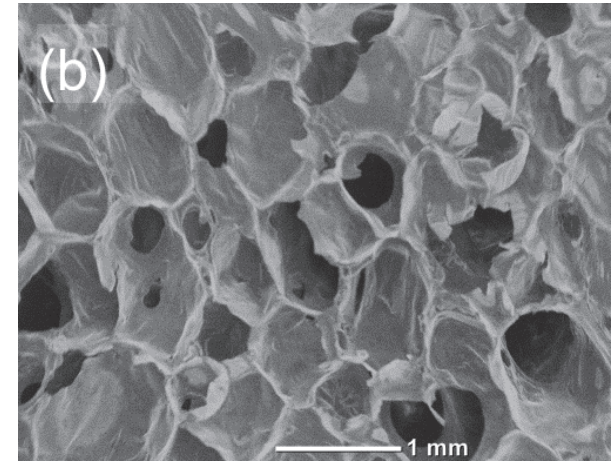

(b)

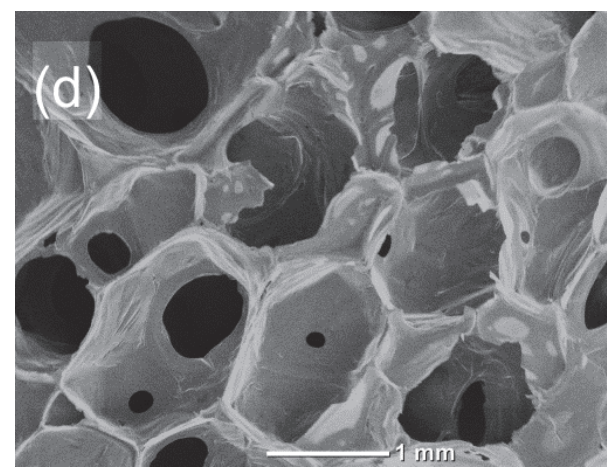

(d)

Figure 1: SEM images of (a) pure polyol, (b) 5\% lignin, (c) 10\% lignin, and (d) 15\% lignin content polyurethane foams.

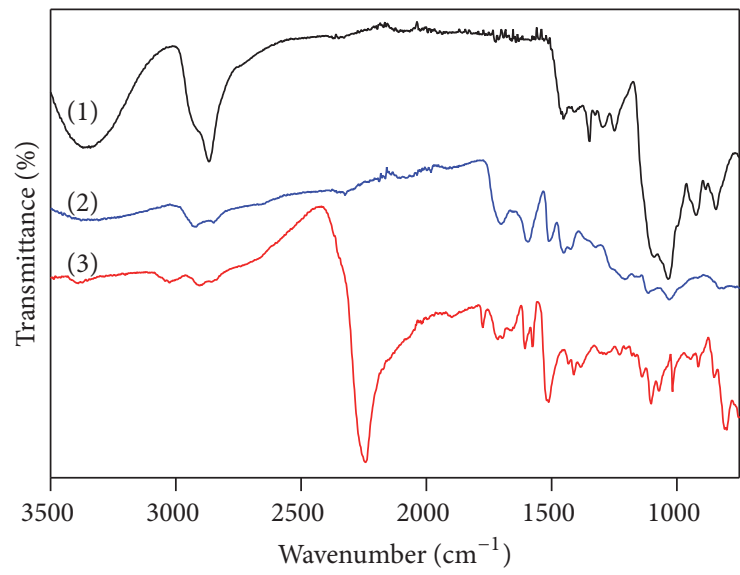

(a)

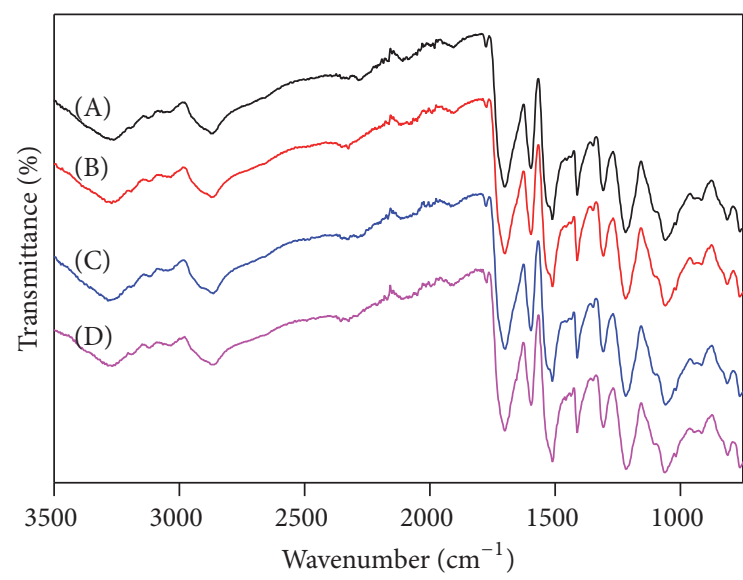

(b)

Figure 2: FTIR spectra of (1) polyol, (2) Switchgrass lignin, and (3) MDI; (A) pure polyol, (B) 5\% lignin, (C) 10\% lignin, and (D) $15 \%$ lignin content polyurethane foams.

TABLE 1: Cell diameter and number of cells by surface area $(n)$ of different polyurethane foams.

\begin{tabular}{lcccc}
\hline Index & \multicolumn{3}{c}{ Lignin content (\%) } & \multicolumn{1}{c}{10} \\
\hline Diameter $(\mu \mathrm{m})$ & 0 & 5 & $521.3 \pm 130.7$ & $838.8 \pm 167.1$ \\
Number of cells by surface area $(n)\left(\mathrm{N} / \mathrm{mm}^{2}\right)$ & $513.4 \pm 112.7$ & $523.1 \pm 89.8$ & 1.87 & 1.02 \\
\hline
\end{tabular}




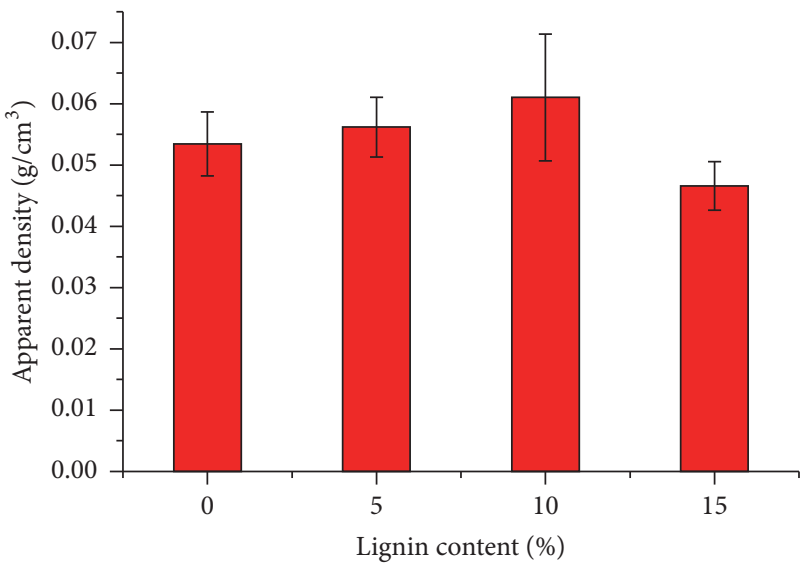

(a)

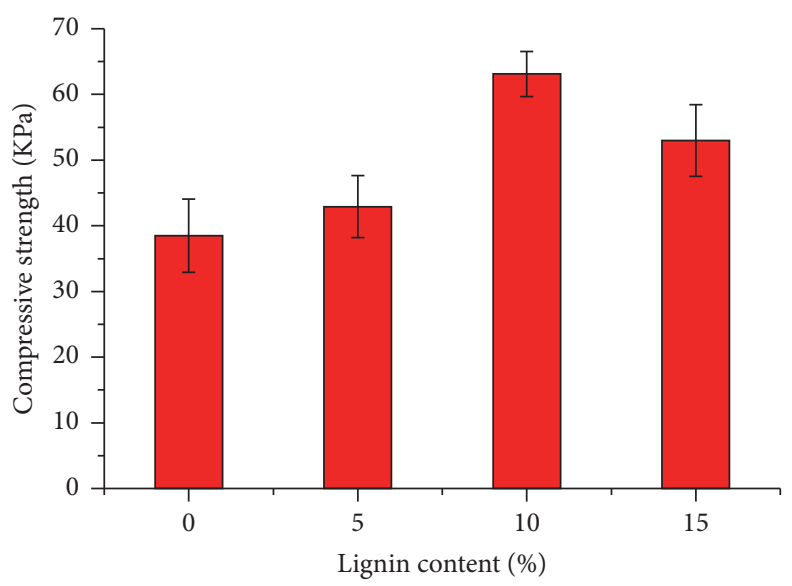

(b)

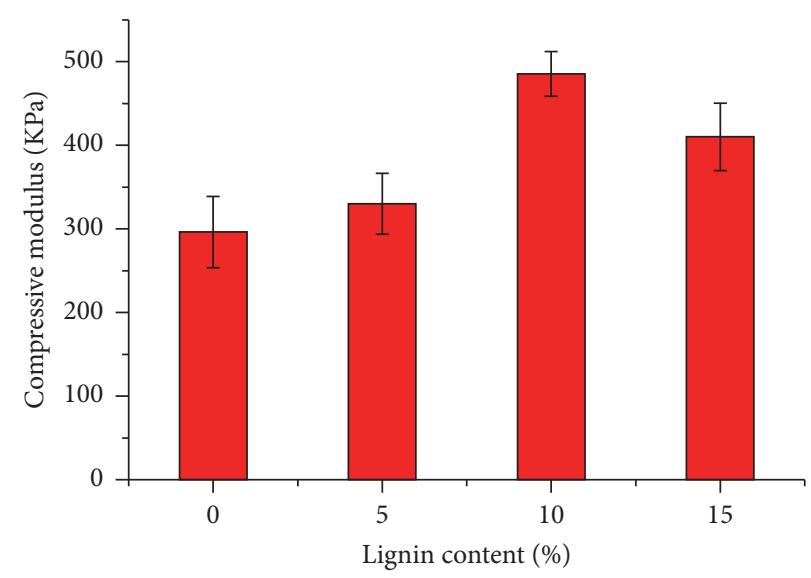

(c)

FigURE 3: Effect of lignin content on (a) apparent density, (b) compressive strength, and (c) compressive modulus of the PU foams.

no significant difference between the control and lignin containing foams, revealing that the main structure of lignin was not altered by the reactions.

3.3. Apparent Density and Mechanical Properties. The apparent density and mechanical properties of the PU foams are shown in Figure 3. The apparent density initially increased and then decreased by increasing the lignin content (Figure 3(a)). The apparent density for the foam with $10 \%$ lignin was the highest, increased by $14.2 \%$ relative to the control foam, while the foam with $15 \%$ lignin showed the lowest density of $0.047 \mathrm{~g} / \mathrm{cm}^{-3}$, which was $12.8 \%$ lower than the control foam. In general, for foams with similar cell wall thickness, density is known to decrease as cell size increases, which further influence mechanical properties [32]. Therefore, the low density for the $15 \%$ lignin foam is due to its large cell size as evidenced by the SEM image (Figure 1(d)). Though the $10 \%$ lignin foam had similar cell size to that for the control, its relatively high density was due to thicker cell walls (Figure 1(c)). As shown in Figures 3(b) and 3(c), by increasing the lignin content to $10 \%$, the compressive strength and compressive modulus increased from 38 and $296 \mathrm{KPa}$ to 63 and $485 \mathrm{KPa}$, respectively; with additional increase in the amount of lignin, the compressive strength and compressive modulus decreased to 53 and $410 \mathrm{KPa}$, respectively. The influence of lignin content on mechanical properties of the foams was similar to that on density. This result also confirmed that density is a prominent parameter determining mechanical properties. It can be concluded that the incorporation of lignin into the PU matrix reinforced the PU foams.

Other researchers also observed an increase in compressive strength and compressive modulus by the introduction of less than $10 \%$ of lignin into foams $[11,18]$. However, lignin was not reinforcement filler in the foam in the report of Xue et al. [30], who argued that lignin was not completely miscible with the polyol, and the uneven mixture of lignin and polyol resulted in irregular cellular structure and thus weakened the mechanical properties. According to other researches $[33,34]$, the addition of $2 \mathrm{wt} \%$ and $1.5 \mathrm{wt} \%$ cellulose and wood flour into foams increased the compressive strength by $21 \%$ and $30 \%$, respectively. In this study, the compressive strength was increased by $63 \%$ with the addition of lignin to the foam. For comparison, the lignin used in this study was significant in reinforcing the mechanical properties of foams with comparison to cellulose and wood flour. The 


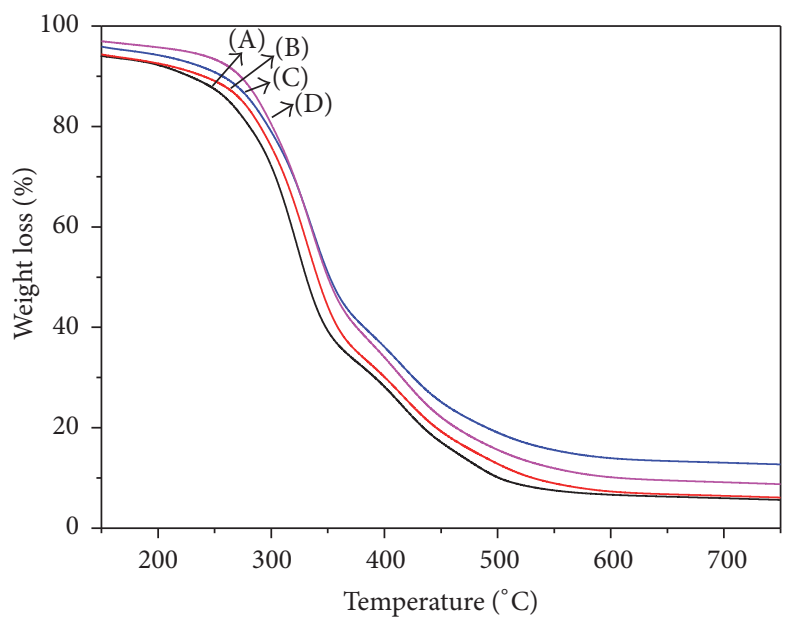

(a)

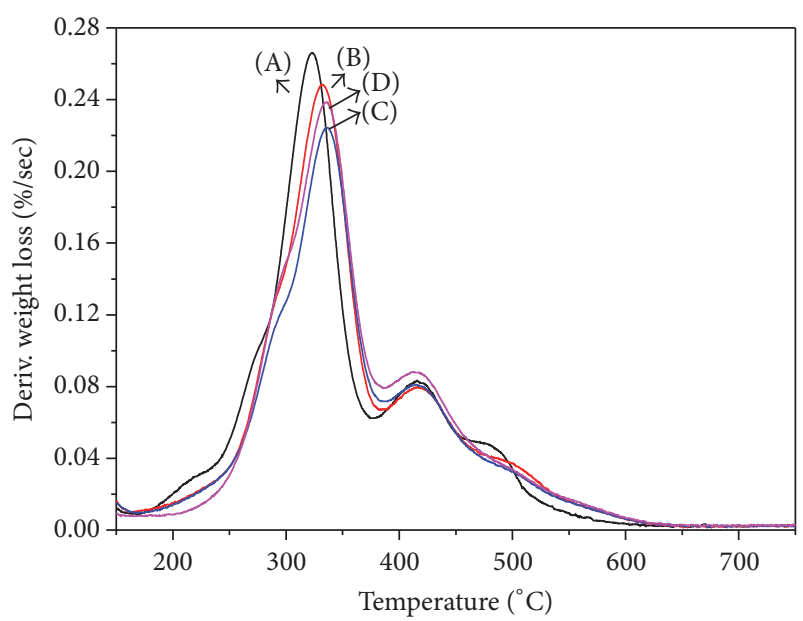

(b)

FIgURE 4: TG and DTG cures of (A) pure polyol, (B) 5\% lignin, (C) 10\% lignin, and (D) 15\% lignin content polyurethane foams.

TABLe 2: Temperature and residue yield of the PU foams with different lignin content.

\begin{tabular}{lccc}
\hline $\begin{array}{l}\text { Lignin } \\
\text { content (\%) }\end{array}$ & $T_{\text {onset }}\left({ }^{\circ} \mathrm{C}\right)$ & $T_{\max }\left({ }^{\circ} \mathrm{C}\right)$ & $\begin{array}{c}\text { Char yield } \\
(\%)\end{array}$ \\
\hline 0 & 133 & 323 & 5.4 \\
5 & 140 & 332 & 5.8 \\
10 & 178 & 335 & 12.4 \\
15 & 224 & 334 & 8.4 \\
\hline
\end{tabular}

significant reinforcement functionality of lignin in the foam may be because lignin is a three-dimensional polymer acting as a compatibilizer in the PU matrix, which resulted in good molecular order of the polyurethane network [31]. With higher lignin content (15\%), the mechanical properties of the foam were decreased, probably due to the lignin macromolecules agglomerating into segments, which reduced the uniform distribution of lignin in the foam. This will result in significant changes in the cellular structure and weaken the strength of the foam [17].

3.4. Thermal Stability. The thermal decomposition behavior of PU foams was evaluated by TG in nitrogen and the TG profiles are presented in Figure 4. All the samples had a narrow degradable temperature range of $350-450^{\circ} \mathrm{C}$. The decomposition processes of both the control and lignin containing foams were divided into two stages corresponding to soft and hard segments, respectively [35], indicating that the addition of lignin into the foams had no significant influence on the degradation mechanism.

The thermal degradation temperatures and char yield are presented in Table 2. The control foam started to decompose at a relative low temperature. $T_{\text {onset }}$ (defined as the temperature at the mass loss of 5\%) significantly increased as the lignin content increased, revealing that lignin in the foam could elevate the initial decomposition temperature primarily because of the thermostable segments produced from interactions between lignin and the PU matrix. The maximum decomposition rate temperature $\left(T_{\max }\right)$ shifted to higher temperatures with the addition of lignin. Though $T_{\max }$ for the foam with $10 \%$ lignin was lower than the PU foam with $19 \%$ soluble ammonium polyphosphate (flame retardant) [36], it was greater than the control foam about $11^{\circ} \mathrm{C}$. As shown in Figure $4(\mathrm{~b})$, the foam with $10 \%$ lignin had particularly high degradation rate at the second peak temperature. This is probably due to the ability of lignin to reinforce the soft phase of the PU matrix resulting in the enrichment of the hard segments. These results indicate that the introduction of lignin into the foam could improve the thermal stability of the foams, and the foam with $10 \%$ lignin had the best thermal stability. A similar result was found in a study of PU foam made from lignin derivatives enriched biopolyol [29].

Char yield showed an increasing trend as the lignin content in the foams increased. Char yield for the foam with $10 \%$ lignin content was more than 2 times that for the control. This is mainly due to the cross-linkage cellular structure and thermostable nature of lignin. The difference in char yield among the control and lignin containing foams further confirmed that lignin acted as thermal filler in the PU foams.

\section{Conclusions}

The addition of less than $10 \%$ of lignin fractionated from microwave liquefied switchgrass into the PU matrix had no significant influence on the microstructures of the PU foam, while higher lignin content (15\%) in the PU matrix resulted in foam with large cell size. FTIR spectra indicated the occurrence of chemical interactions between lignin hydroxyl groups and NCO groups with the production of an extra hydroxyl bond. The foam with $10 \%$ lignin content had the highest apparent density of $0.061 \mathrm{~g} / \mathrm{cm}^{3}$, best mechanical strength (compressive strength and compressive modulus), and superior thermal stability. Further increase of the lignin 
content in the foam resulted in a decline in the apparent density and mechanical properties. The lignin obtained from liquefied switchgrass could be used as reinforcement filler in the preparation of semirigid polyurethane foams.

\section{Conflicts of Interest}

The authors declare there are no conflicts of interest regarding the publication of this paper.

\section{Acknowledgments}

This work is funded by the USDA Forest Service 2015 Wood Innovations Funding Opportunity program, Agreement 15DG-11083150-054.

\section{References}

[1] V. Dolomanova, Jens Chr. M. Rauhe, L. R. Jensen, R. Pyrz, and A. B. Timmons, "Mechanical properties and morphology of nano-reinforced rigid PU foam," Journal of Cellular Plastics, vol. 47, no. 1, pp. 81-93, 2011.

[2] N. Özveren and M. Ö. Seydibeyoğlu, "The use of biodiesel residues for heat insulating biobased polyurethane foams," International Journal of Polymer Science, vol. 2017, Article ID 6310198, pp. 1-14, 2017.

[3] X. Luo, A. Mohanty, and M. Misra, "Lignin as a reactive reinforcing filler for water-blown rigid biofoam composites from soy oil-based polyurethane," Industrial Crops and Products, vol. 47, pp. 13-19, 2013.

[4] C. Zhang and M. R. Kessler, "Bio-based polyurethane foam made from compatible blends of vegetable-oil-based polyol and petroleum-based polyol," ACS Sustainable Chemistry and Engineering, vol. 3, no. 4, pp. 743-749, 2015.

[5] C. Zhang, Y. Xia, R. Chen, S. Huh, P. A. Johnston, and M. R. Kessler, "Soy-castor oil based polyols prepared using a solventfree and catalyst-free method and polyurethanes therefrom," Green Chemistry, vol. 15, no. 6, pp. 1477-1484, 2013.

[6] X. Huang, F. Li, J. Xie et al., "Microwave-assisted Liquefaction of Rape Straw for the Production of Bio-oils," BioResources, vol. 12, no. 1, 2016.

[7] J. Xie, C.-Y. Hse, T. F. Shupe, J. Qi, and H. Pan, "Liquefaction behaviors of bamboo residues in a glycerol-based solvent using microwave energy," Journal of Applied Polymer Science, vol. 131, no. 9, Article ID 40207, 2014.

[8] F. Chen and Z. Lu, "Liquefaction of wheat straw and preparation of rigid polyurethane foam from the liquefaction products," Journal of Applied Polymer Science, vol. 111, no. 1, pp. 508-516, 2009.

[9] S. Hu, C. Wan, and Y. Li, "Production and characterization of biopolyols and polyurethane foams from crude glycerol based liquefaction of soybean straw," Bioresource Technology, vol. 103, no. 1, pp. 227-233, 2012.

[10] R. Gu, M. M. Sain, and S. K. Konar, "A feasibility study of polyurethane composite foam with added hardwood pulp," Industrial Crops and Products, vol. 42, no. 1, pp. 273-279, 2013.

[11] B. Del Saz-Orozco, M. Oliet, M. V. Alonso, E. Rojo, and F. Rodríguez, "Formulation optimization of unreinforced and lignin nanoparticle-reinforced phenolic foams using an analysis of variance approach," Composites Science and Technology, vol. 72, no. 6, pp. 667-674, 2012.
[12] B. C. Saha and M. A. Cotta, "Enzymatic hydrolysis and fermentation of lime pretreated wheat straw to ethanol," Journal of Chemical Technology and Biotechnology, vol. 82, no. 10, pp. 913-919, 2007.

[13] J.-Y. Kim, E.-J. Shin, I.-Y. Eom et al., "Structural features of lignin macromolecules extracted with ionic liquid from poplar wood," Bioresource Technology, vol. 102, no. 19, pp. 9020-9025, 2011.

[14] M. N. S. Kumar, A. K. Mohanty, L. Erickson, and M. Misra, "Lignin and its applications with polymers," Journal of Biobased Materials and Bioenergy, vol. 3, no. 1, pp. 1-24, 2009.

[15] J. Xie, C.-Y. Hse, T. F. Shupe, and T. Hu, "Physicochemical characterization of lignin recovered from microwave-assisted delignified lignocellulosic biomass for use in biobased materials," Journal of Applied Polymer Science, vol. 132, no. 40, Article ID 42635, 2015.

[16] J. Bernardini, I. Anguillesi, M.-B. Coltelli, P. Cinelli, and A. Lazzeri, "Optimizing the lignin based synthesis of flexible polyurethane foams employing reactive liquefying agents," Polymer International, vol. 64, no. 9, pp. 1235-1244, 2015.

[17] X. Pan and J. N. Saddler, "Effect of replacing polyol by organosolv and kraft lignin on the property and structure of rigid polyurethane foam," Biotechnology for Biofuels, vol. 6, article 12, 2013.

[18] Y. Li and A. J. Ragauskas, "Ethanol organosolv lignin-based rigid polyurethane foam reinforced with cellulose nanowhiskers," RSC Advances, vol. 2, no. 8, pp. 3347-3351, 2012.

[19] J. Bernardini, P. Cinelli, I. Anguillesi, M.-B. Coltelli, and A. Lazzeri, "Flexible polyurethane foams green production employing lignin or oxypropylated lignin," European Polymer Journal, vol. 64, pp. 147-156, 2015.

[20] C. Zhang, H. Wu, and M. R. K. Kessler, "High bio-content polyurethane composites with urethane modified lignin as filler," Polymer, vol. 69, no. 1, pp. 52-57, 2015.

[21] B.-L. Xue, J.-L. Wen, and R.-C. Sun, "Producing ligninbased polyols through microwave-assisted liquefaction for rigid polyurethane foam production," Materials, vol. 8, no. 2, pp. 586599, 2015.

[22] I. Lewandowski, J. M. O. Scurlock, E. Lindvall, and M. Christou, "The development and current status of perennial rhizomatous grasses as energy crops in the US and Europe," Biomass and Bioenergy, vol. 25, no. 4, pp. 335-361, 2003.

[23] S. McLauthlin, J. Bouton, D. Bransby et al., "Developing switchgrass as a bioenergy crop," in Perspectives on New Crops and New Uses, J. Janick, Ed., vol. 56, pp. 282-299, ASHS Press, Alexandria, Egypt, 1999.

[24] S. McLaughlin, "New switchgrass biofuels research program for the southeast," in Proceedings of the Proceedings Annual Automotive Development Technology Contractors' Coordination Meeting, pp. 111-115, Dearborn, Mich, USA, 1993.

[25] C. Karunanithy and K. Muthukumarappan, "Optimization of switchgrass and extruder parameters for enzymatic hydrolysis using response surface methodology," Industrial Crops and Products, vol. 33, no. 1, pp. 188-199, 2011.

[26] M. J. Serapiglia, C. A. Mullen, A. A. Boateng, L. M. Cortese, S. A. Bonos, and L. Hoffman, "Evaluation of the impact of compositional differences in switchgrass genotypes on pyrolysis product yield," Industrial Crops and Products, vol. 74, pp. 957968, 2015.

[27] E. M. Karp, M. G. Resch, B. S. Donohoe et al., "Alkaline pretreatment of switchgrass," ACS Sustainable Chemistry and Engineering, vol. 3, no. 7, pp. 1479-1491, 2015. 
[28] N. Wei, B. K. Via, Y. Wang, T. McDonald, and M. L. Auad, "Liquefaction and substitution of switchgrass (Panicum virgatum) based bio-oil into epoxy resins," Industrial Crops and Products, vol. 57, pp. 116-123, 2014.

[29] J. Xie, J. Qi, C.-Y. Hse, and T. F. Shupe, "Effect of lignin derivatives in the bio-polyols from microwave liquefied bamboo on the properties of polyurethane foams," BioResources, vol. 9, no. 1, pp. 578-588, 2014.

[30] B.-L. Xue, J.-L. Wen, and R.-C. Sun, "Lignin-based rigid polyurethane foam reinforced with pulp fiber: synthesis and characterization," ACS Sustainable Chemistry and Engineering, vol. 2, no. 6, pp. 1474-1480, 2014.

[31] C. Ciobanu, M. Ungureanu, L. Ignat, D. Ungureanu, and V. I. Popa, "Properties of lignin-polyurethane films prepared by casting method," Industrial Crops and Products, vol. 20, no. 2, pp. 231-241, 2004.

[32] C. A. Cateto, M. F. Barreiro, C. Ottati, M. Lopretti, A. E. Rodrigues, and M. N. Belgacem, "Lignin-based rigid polyurethane foams with improved biodegradation," Journal of Cellular Plastics, vol. 50, no. 1, pp. 81-95, 2014.

[33] B. Del Saz-Orozco, M. V. Alonso, M. Oliet, J. C. Domínguez, and F. Rodriguez, "Mechanical, thermal and morphological characterization of cellulose fiber-reinforced phenolic foams," Composites Part B: Engineering, vol. 75, pp. 367-372, 2015.

[34] B. Del Saz-Orozco, M. V. Alonso, M. Oliet, J. C. Domínguez, and F. Rodriguez, "Effects of formulation variables on density, compressive mechanical properties and morphology of wood flour-reinforced phenolic foams," Composites Part B: Engineering, vol. 56, pp. 546-552, 2014.

[35] C. Wang, Y. Zhang, L. Lin et al., "Thermal, mechanical, and morphological properties of functionalized graphenereinforced bio-based polyurethane nanocomposites," European Journal of Lipid Science and Technology, vol. 117, no. 12, pp. 19401946, 2015.

[36] W. Yao, H. Wang, D. Guan, T. Fu, T. Zhang, and Y. Dou, “The effect of soluble ammonium polyphosphate on the properties of water blown semirigid polyurethane foams," Advances in Materials Science and Engineering, vol. 2017, Article ID 5282869, pp. 1-7, 2017. 

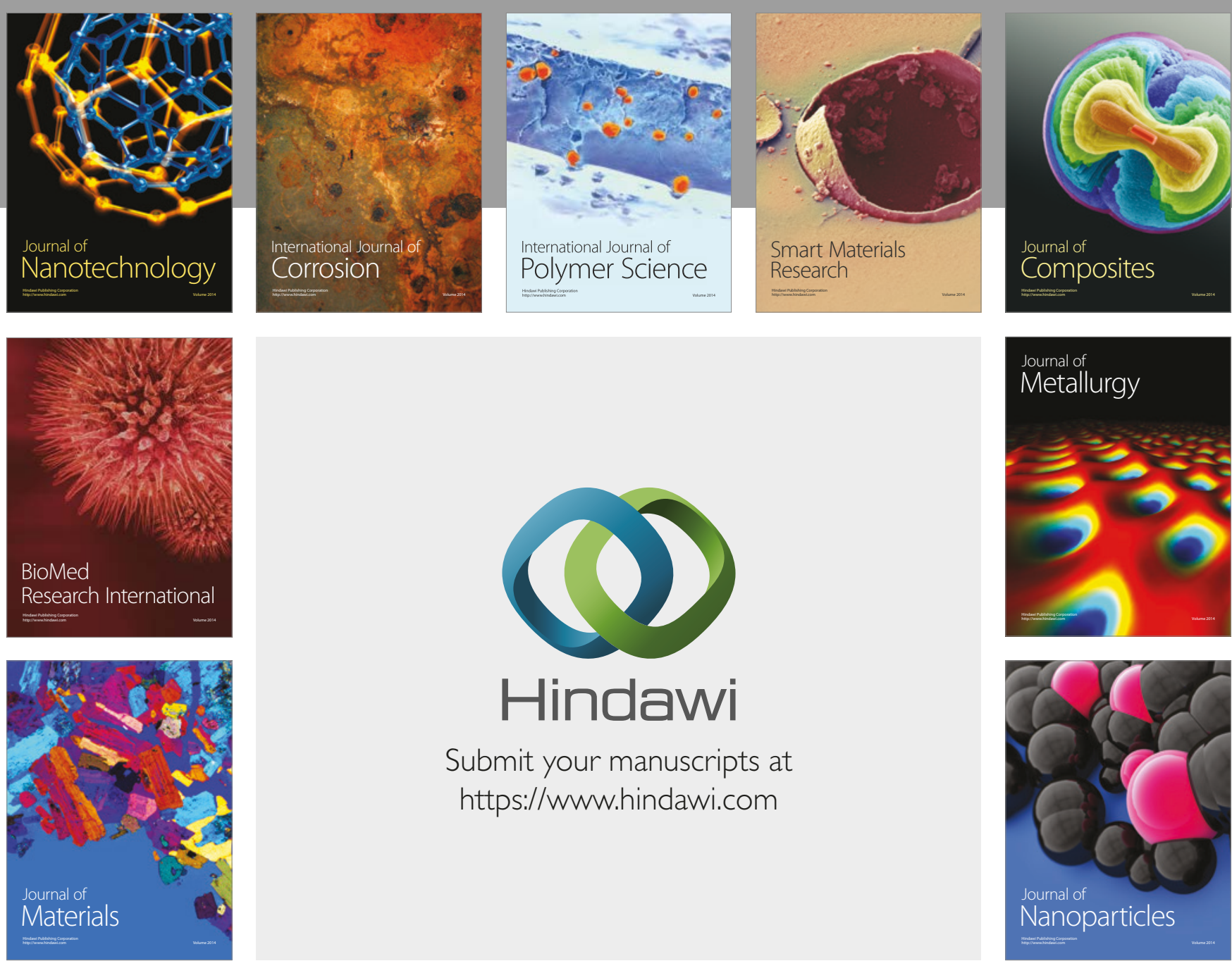

\section{Hindawi}

Submit your manuscripts at

https://www.hindawi.com
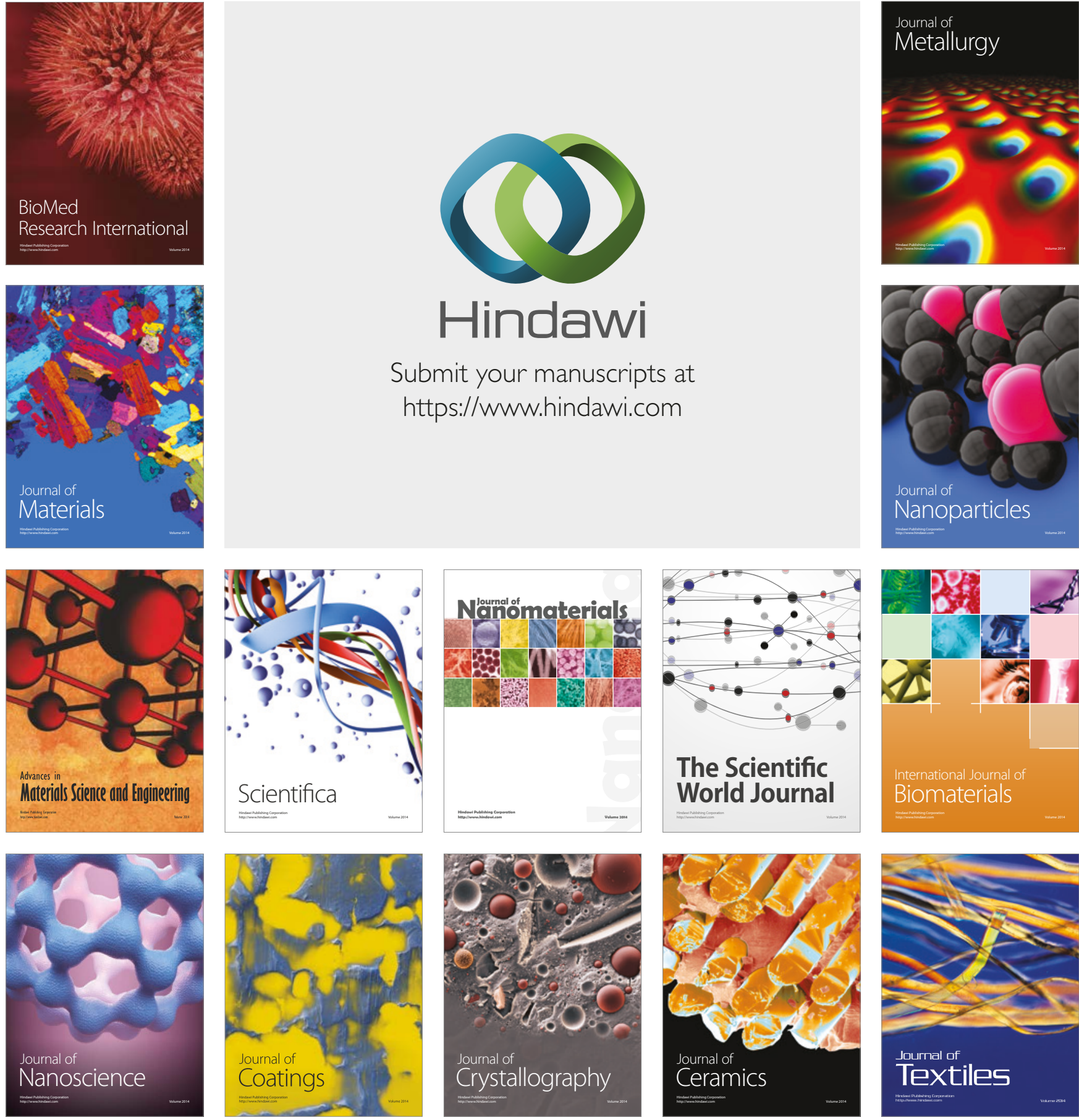

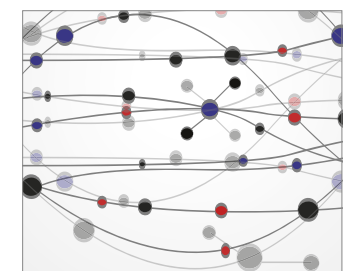

The Scientific World Journal
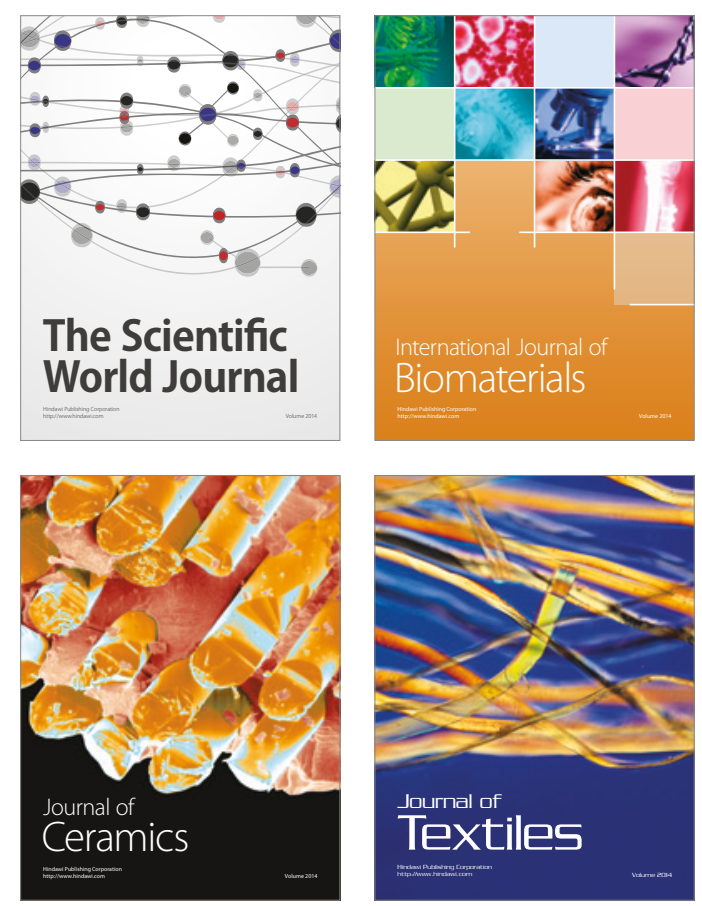